\title{
Ocorrência de Campylobacter em carne de frango, fezes de frango e humanas e pesquisa dos genes $c d t$
}

\author{
[Occurrence of Campylobacter in poultry, meat chicken and human feces, \\ and cdt GENES research] \\ D.T. Silva, T.S. Tejada, C.C. Cunha, N.A. Lopes, A. Agostinetto, T. Collares, \\ P.M.M. Leon, C.D. Timm* \\ Universidade Federal de Pelotas - Pelotas, RS
}

\begin{abstract}
RESUMO
Foram coletadas 100 amostras de conteúdo fecal de aves de corte, 100 de produtos de frango (coxa, sobrecoxa, asa, dorso, carne moída e fígado) e 100 de fezes de humanos, e analisadas para pesquisa de Campylobacter. Realizou-se a determinação da espécie e da presença dos genes $c d t$, responsáveis pela codificação da toxina citoletal distensiva (CDT), através da técnica da PCR. A bactéria foi isolada de $61 \%$ das amostras de fezes de frango, $20 \%$ de produtos de frango e $3 \%$ de fezes de humanos. A maioria dos isolados foi determinada como $C$. jejuni. Destes, $93,5 \%$ apresentaram os genes para a toxina CDT. Apesar de a ocorrência de Campylobacter em fezes de humanos ter sido baixa, a prevalência em frangos de corte e produtos de frango foi elevada, fato que, aliado à presença dos genes $c d t$ na maioria dos isolados, representa risco potencial para os consumidores. Esses resultados são indicativos da necessidade de medidas preventivas no sistema de produção e de boas práticas de fabricação na indústria, de forma a minimizar a contaminação dos produtos e diminuir o risco para os consumidores.
\end{abstract}

Palavras-chave: fezes de frango, Campylobacter, genes $c d t$, fezes de humanos, produtos de frango

\begin{abstract}
A hundred chicken fecal samples, a hundred samples of retail poultry products and a hundred samples of human feces were collected and tested for the presence of Campylobacter. The species identification and the analysis for the presence of cdt genes, responsible for encoding the cytolethal distending toxin, were performed by PCR. Campylobacter was found in $61 \%$ of the chicken fecal samples, in $20 \%$ of the poultry products and in 3\% of the human feces. Most isolates were identified as C. jejuni. In 93.5\% of these isolates, the cdt genes have been detected. Despite the occurrence of Campylobacter in feces of humans has been low, the prevalence in broilers and poultry products was high, which, combined with the presence of cdt genes in most isolates, represents a potential risk to consumers. These results suggest there is a need for preventive measures in the production system and good manufacturing practices in the industry so as to minimize contamination of products and reduce the risk to consumers.
\end{abstract}

Keywords: chicken feces, Campylobacter, cdt genes, human feces, poultry products

\section{INTRODUÇÃO}

A campylobacteriose é uma doença transmitida por alimentos (DTA) para humanos, a qual afeta mais de 2 milhões de pessoas por ano. A maioria dos casos ocorre isoladamente, apresentando quadros que cursam com diarreia, cólicas abdominais e febre. A enfermidade pode ainda levar à Síndrome de Guillain-Barré, uma complicação rara que ocorre em um a cada mil casos da doença, na qual o sistema imune ataca parte do sistema nervoso periférico, causando paralisia muscular. A bactéria Campylobacter, agente etiológico da enfermidade, é encontrada nos alimentos geralmente em baixa concentração, o que, aliado à sensibilidade ao oxigênio, dessecamento, calor, desinfetantes e pH ácido, dificulta o seu

Recebido em 18 de abril de 2013

Aceito em 12 de setembro de 2013

* Autor para correspondência (corresponding author)

E-mail: timm@ufpel.tche.br 
isolamento. A principal espécie envolvida nos casos de campylobacteriose é C. jejuni ((Food..., 2012).

Os frangos podem ser portadores de Campylobacter em seus tratos intestinais, sendo os seus produtos o principal alimento veiculador dessa bactéria para humanos. Esse microorganismo é essencialmente não patogênico para as aves, não representando um problema para os sistemas de produção avícola, o que faz com que seu controle seja negligenciado nos aviários (Germano e Germano, 2003). No Brasil, as porcentagens de contaminação em fezes de frango podem chegar a 96,6\% (Chaves et al., 2010).

Normalmente, o isolamento de Campylobacter a partir de produtos de frango é menor que o isolamento em fezes. Higiene e medidas de controle dentro da indústria são práticas que reduzem a contaminação inicial da carcaça, mas são insuficientes para eliminar a bactéria do produto final (Kuana et al., 2008). A Campylobacter pode ser encontrada em diversos pontos dentro da linha de abate de frangos; com isso, lotes livres de contaminação inicial podem se contaminar durante o processamento, mesmo que tenham sido abatidos em dias subsequentes (Perko-Mäkelä et al., 2011). Pesquisas mostram prevalências de 32,6 a $93,7 \%$ em produtos de frango vendidos no mercado (Carvalho e Cortez, 2003; Freitas e Noronha, 2007).

A ocorrência de Campylobacter em humanos, no Brasil, ainda está pobremente estabelecida. Dois estudos, desenvolvidos por Lima et al. (1993) e Scarcelli et al. (1998), encontraram $12 \%$ de portadores em Recife e 25,9\% em São Paulo, respectivamente.

Um dos fatores de patogenicidade da bactéria, responsável pelos sinais clínicos em humanos, é a toxina citoletal distensiva (CDT). Essa toxina é composta pelas subunidades proteicas cdtA, cdtB e cdtC, codificadas pelos genes $c d t \mathrm{~A}, c d t \mathrm{~B}$ e $c d t \mathrm{C}$, respectivamente. É necessária a expressão dos três genes para que a proteína esteja na sua forma ativa e possa penetrar nas células. A subunidade cdtB é o componente tóxico, que atua como uma DNase. CdtB chega até o núcleo da célula intestinal e leva à quebra da fita dupla de DNA, provocando a morte celular. As funções das porções cdtA e cdtC ainda não são claras, mas parece serem responsáveis pela ligação a receptores celulares e endocitose. Mutações nos genes $c d t$ podem causar perda de função, impedindo, dessa forma, que ocorram os danos celulares (Young et al., 2007).

Os trabalhos realizados no Brasil, com vistas ao isolamento de Campylobacter a partir de fezes de frangos, de alimentos e de fezes humanas, são poucos e apresentam resultados variáveis. Adicionalmente, não foram feitos estudos de virulência, não havendo garantias de que os isolados obtidos tenham potencial patogênico para humanos e possam causar DTA. A pesquisa de Campylobacter em diferentes pontos da cadeia epidemiológica, identificando características dos isolados importantes para a patogenicidade da doença, constituem significativo avanço no conhecimento da campylobacteriose alimentar.

Este trabalho teve como objetivo verificar a presença de $C$. jejuni e $C$. coli em carne de frango, fezes de frango e humanas e pesquisar a presença dos genes $c d t \mathrm{~A}, c d t \mathrm{~B}$ e $c d t \mathrm{C}$ nos isolados.

\section{MATERIAL E MÉTODOS}

Foram coletadas 100 amostras de fezes da porção final do intestino de frangos de corte, com idade entre 40 a 45 dias, oriundos de 20 aviários (cinco amostras de cada), 100 produtos de frango in natura (20 de coxa/sobrecoxa, 20 de asa, 20 de dorso, 20 de carne moída e 20 de fígado) coletados no comércio varejista do Sul do Brasil e 100 amostras de fezes de humanos. Todas as amostras foram coletadas na região sul do estado do Rio Grande do Sul.

As amostras de fezes de frango foram obtidas em abatedouro legalmente estabelecido, oficialmente inspecionado por Médico Veterinário da Coordenadoria de Inspeção Sanitária dos Produtos de Origem Animal da Secretaria de Agricultura, Pecuária e Agronegócio do Estado do Rio Grande do Sul, imediatamente após o procedimento de abate pelo pessoal do abatedouro, conforme as normas legais. As fezes de humanos foram obtidas com o consentimento por escrito das pessoas que as encaminharam para análise laboratorial. 
As amostras de fezes de frango e humanas foram coletadas com o uso de zaragatoas estéreis e encaminhadas ao laboratório em meio de transporte Cary Blair (Himedia, Mumbai, Índia), em caixas isotérmicas com gelo. As fezes de frango foram obtidas da porção final do intestino das aves imediatamente após o abate. As fezes de humanos foram coletadas de material enviado a laboratórios de análises clínicas para análise parasitológica. Os produtos de frango foram encaminhados ao laboratório em caixas isotérmicas com gelo, acondicionados nas embalagens de venda.

Para o isolamento, cada produto de frango foi colocado em sacos plásticos estéreis contendo $50 \mathrm{~mL}$ de Caldo Brucella (Acumedia, Lansing, Michigan, USA) e massageado durante $2 \mathrm{~min}$. Uma alíquota desse caldo foi semeada na superfície de Columbia Blood Agar Base (Acumedia) adicionado de $0,4 \%(\mathrm{~m} / \mathrm{v})$ de carvão ativado, $5 \%(\mathrm{~m} / \mathrm{v})$ de suplemento de solução redutora de oxigênio FBP (George et al., 1978) e $1 \%(\mathrm{~m} / \mathrm{v})$ de suplemento Campylobacter I (Blaser - Wang) (Himedia), que contém antibióticos para controlar o crescimento da microbiota acompanhante. As zaragatoas com as amostras de fezes foram diretamente semeadas em superfície de ágar Columbia com as adições mencionadas.

As incubações foram realizadas em microaerofilia a $42^{\circ} \mathrm{C}$ por 48 horas. A atmosfera de microaerofilia foi gerada através de uma modificação sugerida por Filgueiras e Hofer (1989) da técnica de passivação do cobre descrita por Attebery e Finegold (1970). Adaptada proporcionalmente a uma jarra de $2,5 \mathrm{~L}$, essa técnica consiste em triturar $2,8 \mathrm{~g}$ de Sonrisal (Sanofi-Winthrop Farmacêutica), colocar em uma base de placa de Petri e, sobre este, colocar $7,1 \mathrm{~g}$ de palha de aço $\left(\right.$ Bombril $^{\circledR}$ ) embebida em solução acidulada de sulfato de cobre. Com esse preparo, obtém-se uma concentração final de $85 \% \mathrm{~N}_{2}, 10 \% \mathrm{CO}_{2}$ e $5 \% \mathrm{O}_{2}$.

As colônias com brilho d'água e espraiadas foram analisadas morfotintorialmente pela coloração de Gram. Naquelas em que foram observados bastonetes delgados, em forma de $\mathrm{S}$ ou de "asa de gaivota", foram realizados testes das enzimas catalase e oxidase. As colônias com características de Campylobacter foram repicadas para nova cultura em ágar Columbia. Quando não foram obtidas culturas puras, as colônias foram raspadas da superfície do ágar e, após suspensão em solução salina a $0,85 \%$, foram filtradas em filtro de $0,45 \mu \mathrm{m}$ (Sartorius Stedim Biotech, Goettingen, Germany) para separação dos contaminantes e foram novamente cultivadas.

As culturas puras suspeitas de Campylobacter foram criopreservadas em meio estoque (glicerol $25 \mathrm{~mL}$, neopeptona $1 \mathrm{~g}, \mathrm{NaCl} 0,5 \mathrm{~g}$, água destilada $75 \mathrm{~mL}$ ). Os isolados foram recuperados em ágar Columbia a $42^{\circ} \mathrm{C}$ por 48 horas, em microaerofilia, quando necessário.

A confirmação dos isolados suspeitos foi realizada através da técnica da Reação em Cadeia da Polimerase (PCR). O DNA foi extraído com kit comercial Ilustra Bacteria GenomicPREP Mini Spin Kit (GE Healthcare, Buckinghamshire, UK), de acordo com as recomendações do fabricante, a partir de um pélete de colônias obtido diretamente das placas. O DNA foi analisado através da técnica de multiplex PCR para identificação das espécies $C$. jejuni e $C$. coli, de acordo com protocolo descrito por Harmon et al. (1997). Foram utilizados dois pares de primers (Tab. 1): par pg 3/pg 50, que amplificam uma região altamente conservada relacionada aos genes da flagelina, tanto em $C$. jejuni como em $C$. coli, e o par C-1/C-4, que amplificam uma região específica somente presente em $C$. jejuni. Cada reação teve um volume final de $25 \mu \mathrm{L}$. Foram utilizados $12 \mu \mathrm{L}$ de Master Mix (Promega, Madison, Wisconsin, USA), $2 \mu \mathrm{L}$ (20pmol) de cada primer, $1 \mu \mathrm{L}$ de DNA (na concentração de $5 \mathrm{nmol} / \mu \mathrm{L}$ ) e $4 \mu \mathrm{L}$ de água para completar o volume da reação. A amplificação foi realizada em termociclador TC3000 (Techne) com o seguinte programa: desnaturação inicial de $94^{\circ} \mathrm{C}$ por $4 \mathrm{~min}$, seguido de 25 ciclos de desnaturação a $94^{\circ} \mathrm{C}$ por $1 \mathrm{~min}$, anelamento dos primers a $45^{\circ} \mathrm{C}$ por $1 \mathrm{~min}$, extensão a $72^{\circ} \mathrm{C}$ por 1 min e extensão final a $72^{\circ} \mathrm{C}$ por $7 \mathrm{~min}$. Como controle positivo, foi utilizada a cepa de $C$. jejuni ATCC 33291 e a cepa $C$. coli CCAMP1003, gentilmente cedidas pelo setor de Campylobacter do Instituto Oswaldo Cruz do Rio de Janeiro. Para análise das amplificações, foi utilizada a técnica de eletroforese em gel de agarose a 1,5\%. Para visualização das bandas utilizou-se GelRed (Uniscience, São Paulo, São Paulo, Brasil), um corante de ácido nucleico que emite fluorescência na presença de luz ultravioleta. 
Tabela 1. Primers usados na diferenciação de $C$. jejuni e $C$. coli

\begin{tabular}{lccc}
\hline Primer & \multicolumn{1}{c}{ Sequência (5' a 3') } & Espécie & $\begin{array}{c}\text { Tamanho da amplificação na PCR } \\
(\mathrm{pb})\end{array}$ \\
\hline Pg 3 & GAACTTGAACCGATTTG & C. coli & 460 \\
Pg 50 & ATGGGATTTCGTATTAAC & C. jejuni & 480 \\
& & & 160 \\
C-1 & CAAATAAAGTTAGAGGTAGAATGT & C. jejuni & \\
C-4 & GGATAAGCACTAGCTAGCTGAT & & \\
\hline
\end{tabular}

Após a identificação da espécie, foi feita a pesquisa de genes de virulência também através da técnica de multiplex PCR, de acordo com Martinez et al. (2006), utilizando primers específicos para os genes $c d t \mathrm{~A}, c d t \mathrm{~B}$ e $c d t \mathrm{C}$ (Tab. 2). Para um volume final de $25 \mu \mathrm{L}$, foram utilizados $12 \mu \mathrm{L}$ de Master Mix, $2 \mu \mathrm{L}$ (20pmol) de cada primer e $1 \mu \mathrm{L}(5 \mathrm{nmol} / \mu \mathrm{L})$ de DNA. A amplificação foi realizada com uma desnaturação inicial de $94^{\circ} \mathrm{C}$ por $5 \mathrm{~min}$, seguida de 30 ciclos de desnaturação a $94^{\circ} \mathrm{C}$ por $1 \mathrm{~min}$, anelamento a $57^{\circ} \mathrm{C}$ por $1 \mathrm{~min}$, extensão a $72^{\circ} \mathrm{C}$ por 1 min e extensão final a $72^{\circ} \mathrm{C}$ por $5 \mathrm{~min}$. Para análise do produto amplificado, foi utilizada mesma técnica já descrita anteriormente.

Tabela 2. Primers usados na pesquisa dos genes $c d t \mathrm{~A}, c d t \mathrm{~B}$ e $c d t \mathrm{C}$

\begin{tabular}{lcc}
\hline Primer & Sequência (5' a 3') & Tamanho da amplificação na PCR $(\mathrm{pb})$ \\
\hline$c d t \mathrm{~A}-\mathrm{F}$ & CTATTACTCCTATTACCCCACC & 422 \\
$c d t \mathrm{~A}-\mathrm{R}$ & AATTTGAACCGCTGTATTGCTC & \\
& & 531 \\
$c d t \mathrm{~B}-\mathrm{F}$ & AGGAACTTTACCAAGAACAGCC & \\
$c d t \mathrm{~B}-\mathrm{R}$ & GGTGGAGTATAGGTTTGTTGTC & 339 \\
& & \\
$c d t \mathrm{C}-\mathrm{F}$ & ACTCCTACTGGAGATTTGAAAG & \\
$c d t \mathrm{C}-\mathrm{R}$ & CACAGCTGAAGTTGTTGTTGGC & \\
\hline
\end{tabular}

\section{RESULTADOS E DISCUSSÃO}

Das 100 amostras de fezes de frango analisadas, foram isolados Campylobacter spp. de 61 (61\%) amostras de 17 dos 20 aviários estudados. Seis aviários apresentaram todas as amostras positivas para Campylobacter. Dos outros 11 aviários em que a bactéria foi isolada, observaram-se quatro com quatro amostras positivas, três com três, três com duas e dois com uma. Os resultados observados estão de acordo com as prevalências encontradas em outros trabalhos, como $75,8 \%$ no Reino Unido (Powell et al., 2012) e 76\% no Irã (Ansari-Lari et al., 2011). Prevalências maiores têm sido citadas em estudos realizados no Brasil. Chaves et al. (2010), no Pará, isolaram Campylobacter de 96,6\% de amostras de cloaca de frangos. No Rio Grande do Sul, Kuana et al. (2008) encontraram $81 \%$ de contaminação em frangos de uma granja. Esses valores elevados se devem ao fato de a bactéria ter a capacidade de se disseminar rapidamente dentro dos aviários (Evans e Sayers, 2000).
Dos 41 isolados de fezes de frango estudados (20 isolados foram identificados, mas, devido à dificuldade de cultivo da bactéria, não foi possível obter material para análise molecular), $35(85,4 \%)$ foram identificados como C. jejuni, e seis $(14,6 \%)$ como C. coli. Considerando os aviários positivos para Campylobacter, 12 apresentaram apenas $C$. jejuni $(70,6 \%)$, um somente C. coli $(5,9 \%)$ e outro apresentou as duas espécies $(5,9 \%)$. Três aviários não puderam ter as espécies identificadas devido à dificuldade de cultivo do micro-organismo. Resultados semelhantes foram encontrados no estudo de Heuer et al. (2001), que analisaram as espécies de Campylobacter distribuídas em lotes de frangos de corte portadores da bactéria. Esses autores encontraram $87,5 \%$ dos lotes com $C$. jejuni, $10 \%$ com C. coli e somente $2,5 \%$ com infecção mista. A observação das duas espécies concomitantemente em aves do mesmo aviário parece não ser uma ocorrência comum. 
A Campylobacter é frequentemente encontrada em produtos cárneos de frango, sendo a contaminação dos alimentos a principal causa da campylobacteriose em humanos. Frangos portadores de Campylobacter são responsáveis pela contaminação de carcaças durante o processamento, especialmente durante a etapa de evisceração, e através da contaminação cruzada (Powell et al., 2012). Das 100 amostras de produtos de frango analisadas, Campylobacter foi isolada de $20(20 \%)$ amostras, sendo $11 C$. jejuni e quatro $C$. coli (Tab. 3). Cinco isolados não puderam ser identificados. Vários estudos reportam prevalências elevadas de Campylobacter em carnes de frango, como $81 \%$ na Itália (Pezzotti et al., 2003) e 83\% no Reino
Unido (Kramer et al., 2000). No Brasil, no estado do Pará, Freitas e Noronha (2007) isolaram Campylobacter spp. de 93,7\% das amostras de carne e miúdos de frango analisadas. Os valores encontrados em nosso estudo são mais baixos do que esses percentuais, o que pode estar relacionado à adoção de boas práticas de fabricação na indústria, uma vez que a ocorrência observada em frangos foi relativamente alta. Os produtos de frango que apresentaram maior contaminação foram os fígados. Essa contaminação pode ser decorrente de falhas no processo de evisceração das carcaças, etapa do processamento com alto risco de contaminação, considerando a proximidade do órgão com o trato gastrointestinal.

Tabela 3. Amostras positivas para Campylobacter em carne de frango e presença dos genes $c d t$ nas espécies isoladas

\begin{tabular}{lcccccc} 
& $\mathrm{N}^{\circ}$ de & Isolamento de & \multicolumn{4}{c}{ Espécie / gene } \\
\cline { 4 - 7 } Produtos de frango & amostras & Campylobacter & C. jejuni & $c d t$ & C. coli & $c d t$ \\
\hline Fígado & 20 & 11 & 6 & 5 & 2 & 0 \\
Dorso & 20 & 5 & 2 & 2 & 1 & 0 \\
Asa & 20 & 3 & 2 & 2 & 1 & 0 \\
Coxa/Sobrecoxa & 20 & 1 & 1 & 1 & 0 & 0 \\
Carne moída & 20 & 0 & 0 & 0 & 0 & 0 \\
Total & 100 & 20 & 11 & 10 & 4 & 0 \\
\hline
\end{tabular}

A C. jejuni foi a espécie mais encontrada em todos os tipos de amostras analisadas. Essa é a espécie predominante em fezes de frangos de corte (Hald et al., 2000). A C. jejuni é também a espécie mais frequente em produtos de frango e o principal causador das enterites humanas (Kramer et al., 2000; Pezzotti et al., 2003).

Das 100 amostras de fezes humanas analisadas, 40 amostras eram de pessoas com idade até cinco anos, 36 de pessoas entre cinco e 20 anos, 11 entre 20 e 60, e 13 com mais de 60 anos. Foram encontrados $3 \%$ de amostras positivas para Campylobacter, mas somente um isolado pôde ser estudado, o qual foi identificado como $C$. jejuni. As idades das pessoas portadoras de Campylobacter foram 1, 4 e 31 anos, sendo o isolado estudado de uma mulher de 31 anos. A maior incidência de campylobacteriose ocorre em crianças abaixo de 2 anos de idade (Jofre e Espinoza, 2008). Quertz et al. (2010) realizaram um estudo com crianças de 2 a 36 meses e isolaram Campylobacter de 10,6\% das crianças que apresentaram diarreia, e de $8,4 \%$ das crianças sem sintomatologia. Segundo Lima et al. (1993), a enfermidade acomete $12 \%$ das crianças menores de 5 anos, cursando com quadros diarreicos. Em nosso estudo, duas das três pessoas que albergavam Campylobacter tinham idade inferior a 5 anos, entretanto a ocorrência de $C$. jejuni em um adulto é indicativo da importância que indivíduos dessa faixa etária podem ter na epidemiologia da campylobacteriose. Devido à forma de obtenção das amostras no nosso estudo, não foi possível avaliar o quadro clínico das pessoas cujas amostras foram analisadas, mas pode-se presumir que as pessoas que encaminharam fezes para exame laboratorial parasitológico apresentassem algum tipo de desconforto ou patologia intestinal.

Uma pesquisa no estado de Santa Catarina mostrou que $6,2 \%$ da população de adultos pode ser portadora assintomática de Campylobacter (Tosin e Machado, 1995). A ocorrência encontrada em humanos no Brasil pode ser considerada baixa quando comparada a estudos desenvolvidos em outros países. O trabalho de Hãnninen et al. (2000), desenvolvido na Finlândia durante três anos consecutivos, de 1996 a 1998, encontrou uma variação na 
incidência de casos de campylobateriose em humanos de 89, 36 e 69\% para cada ano, respectivamente. Nos Estados Unidos, no mesmo período, a incidência foi mais baixa, com valores de $23,6,25,2$ e $21,4 \%$, respectivamente, em cada ano (Samuel et al., 2004). Uma possível explicação para a baixa ocorrência no Brasil é que as cepas prevalentes em humanos sejam sensíveis aos antibióticos utilizados nos meios de cultivo seletivo. Outra explicação é que a exposição à bactéria desde criança pode fazer com que o organismo produza anticorpos específicos contra Campylobacter, diminuindo assim a infecção em indivíduos adultos.

Todos os isolados estudados que apresentaram genes $c d t$ possuíam os três genes, $c d t \mathrm{~A}, c d t \mathrm{~B}$ e $c d t$ C. Trinta e três $(91,7 \%)$ dos 35 C. jejuni isolados de fezes de frangos continham os genes $c d t$. Dez dos $11 C$. jejuni isolados de produtos de frango, assim como o $C$. jejuni isolado de humano, também apresentaram os genes para a produção da toxina CDT. Estudos com amostras clínicas de $C$. jejuni têm demonstrado que a maioria dos isolados é produtora de CDT (Martínez et al., 2006; Van Deun et al., 2007). A patogenia da campylobacteriose em humanos ainda não é bem conhecida, mas há uma correlação entre a produção de CDT e casos da doença em humanos, sendo essa toxina um dos fatores de virulência associado às infecções (Van Deun et al., 2007). Jain et al. (2008) demonstraram que as cepas de Campylobacter produtoras de CDT apresentam alto poder de aderência, capacidade invasiva e citotoxicidade frente a células HeLa. Esses autores também estudaram a atividade de cepas de Campylobacter CDT positivas e CDT negativas através da inoculação em camundongos. Os camundongos inoculados com cepas CDT positivas provocaram grande destruição celular e intensa resposta inflamatória nos tecidos intestinais. Os camundongos inoculados com cepas CDT negativo, por sua vez, apresentaram apenas uma leve inflamação, sem danos significativos aos tecidos gastrointestinais. Portanto, embora a capacidade da bactéria de provocar doença independa da produção da toxina, o risco para o consumidor está aumentado quando da ocorrência de cepas portadoras dos genes $c d t$, pois a intensidade da patologia da enfermidade será exacerbada.

Nenhum isolado de C. coli apresentou os genes $c d t$. Rozynek et al. (2005) também observaram que cepas de $C$. coli isoladas de crianças com diarreia não apresentavam genes $c d t$.

Os resultados obtidos neste estudo são indicativos da necessidade de medidas preventivas no sistema de produção, de forma a diminuir a contaminação dos frangos para que esta possa ser eliminada durante o processamento. $\mathrm{Na}$ indústria, procedimentos rigorosos devem ser implementados com vistas à segurança alimentar, sendo fundamental a adoção de boas práticas de fabricação, conforme demonstrado no estudo de Kuana et al. (2008), em que a aplicação dessas medidas resultaram na redução de produtos de frango contaminados por Campylobacter.

A maioria dos países desenvolvidos da Europa e América do Norte tem programas de vigilância para Campylobacter e outras bactérias patogênicas transmitidas por alimentos. Estabelecer programas semelhantes em países em desenvolvimento poderia colaborar para $\mathrm{o}$ controle da disseminação da bactéria.

\section{CONCLUSÕES}

A prevalência de Campylobacter em frango de corte na região sul do Rio Grande do Sul é elevada, e um percentual importante dos produtos de frango oferecidos ao consumo na região estão contaminados por esse patógeno. $C$. jejuni é a espécie predominante, tanto nos aviários como nos produtos de frango, sendo que a maioria das cepas apresenta potencial para produção da toxina CDT.

\section{AGRADECIMENTOS}

Ao Conselho Nacional de Desenvolvimento Científico e Tecnológico (CNPq) pelo financiamento do trabalho. 


\section{REFERÊNCIAS}

ANSARI-LARI, M.; HOSSEINZADEH, S.; SHEKARFOROUSH, S.S. et al. Prevalence and risk factors associated with campylobacter infections in broiler flocks in Shiraz, southern Iran. Int. J. Food Microbiol., v.144, p.475-479, 2011.

ATTEBERY, H.R.; FINEGOLD, S.M. A miniature anaerobic jar for tissue transport or for cultivation of anaerobes. Am. J. Clin. Pathol., v.53, p.383-388, 1970.

CARVALHO, A.C.F.B.; CORTEZ, A.L.L. Contaminação de produtos avícolas industrializados e seus derivados por Campylobacter jejuni e Salmonella sp. ARS Vet., v.19, p.57-62, 2003.

CHAVES, S.O.C.; SOUZA, C.O.; FREITAS, J.A. et al. Ocorrência de Campylobacter em granjas e abatedouro avícola na mesorregião metropolitana de Belém, PA, BR. Cienc. Anim. Bras., v.11, p.554-560, 2010.

EVANS, S.J.; SAYERS, A.R. A longitudinal study of campylobacter infection of broiler flocks in Great Britain. Prev. Vet. Med., v.46, p.209-223, 2000.

FILGUEIRAS, A.L.L.; HOFER, E. Ocorrência de Campylobacter termofilico em diferentes pontos de uma estação de tratamento de esgotos na cidade do Rio de Janeiro. Rev. Microbiol., v.20, p.303-308, 1989.

FOOD and Drug Administration [FDA]. Department of Health and Human Services. Campylobacter jejuni. In: Bad Bug Book: Foodborne Pathogenic Microorganisms and Natural Toxins Handbook, 2012. Disponível em: <http://www.fda.gov/Food/ FoodSafety/FoodborneIllness/FoodborneIllnessFoodb ornePathogensNaturalToxins/BadBugBook/ucm07002 4.htm> Acessado em: 4 jun. 2012.

FREITAS, J.A.; NORONHA, G.N. Ocorrência de Campylobacter spp. em carne e miúdos de frango expostos ao consumo em Belém, Pará. Arq. Bras. Med. Vet. Zootec., v.59, p.813-815, 2007.

GEORGE, H.A.; HOFFMANN, P.S.; KRIEG, N.R.; SMIMBERT, R.M. Improved media for growth and aerotolerance of Campylobacter fetus. J. Clin. Microbiol. v.8, p.36-41, 1978.

GERMANO, P.M.L.; GERMANO, M.I.S. Agentes bacterianos de toxinfecções. In: GERMANO, P.M.L.; GERMANO, M.I.S. Higiene e Vigilância Sanitária de Alimentos. 2. ed., São Paulo:Varela, 2003. p.215-275.

HALD, B.; WEDDERKOPP, A.; MADSEN, M. Thermophilic Campylobacter spp. in Danish broiler production: a cross-sectional survey and a retrospective analysis of risk factors for occurrence in broiler flocks. Avian Pathol., v.29, p.123-131, 2000.
HÃNNINEN, M.; PERKO-MÃKELA, P.; PITKÃLÃ, A.; RAUTELIN, H. A three-year study of Campylobacter jejuni genotypes in humans with domestically acquired infections and in chicken samples from the Helsinki area. J. Clin. Microbiol., v.38, p.1998-2000, 2000.

HARMON, K.M.; RANSOM, G.M.; WESLEY, I.V. Differentiation of Campylobacter jejuni and Campylobacter coli by polymerase chain reaction. Mol. Cell. Probes, v.11, p.195-200, 1997.

HEUER, O.E.; PEDERSEN, K.; ANDERSEN, J.S.; MADSEN, M. Prevalence and antimicrobial susceptibility of thermophilic Campylobacter in organic and conventional broiler flocks. Lett. App. Microbiol., v.33, p.269-274, 2001.

KRAMER, J.M.; FROST, J.A.; BOLTON， F.J.; WAREING, D.R.A. Campylobacter contamination of raw meat and poultry at retail sale: identification of multiple types and comparison with isolates from human infection. J. Food Protect., v.63, p.1654-1659, 2000.

KUANA, S.L.; SANTOS, L.R.; BEATRIZ, L. et al. Ocorrência de Campylobacter em lotes de frangos de corte e nas carcaças correspondentes. Cienc. Anim. Bras., v.9, p.480-486, 2008.

JAIN, D.; PRASAD, K.N.; SINHA, S.; HUSAIN, N. Differences in virulence attributes between cytolethal distending toxin positive and negative Campylobacter jejuni strains. J. Med. Microbiol., v.57, p.267-272, 2008.

JOFRE, K.J.M.; ESPINOZA, C.P. Prevalencia de especies de Campylobacter spp. Em niños menores de 10 años com diarrea aguda en la ciudad de Talca., 2008. Disponível em: <http://dspace.utalca.cl/handle/1950/5697> Acessado em: 15 dez. 2011

LIMA, N.V.; FIGUEIREDO, A.C.T.A.; PRADO, A.D. et al. Campylobacter e outros enteropatogenos em processos diarreicos infantis no Recife, Pernambuco. Rev. Bras. Anal. Cli., v.25, p.71-74, 1993.

MARTINEZ, I.; MATEO, E.; CHURRUCA, E. et al. Detection of $c d t \mathrm{~A}, \quad c d t \mathrm{~B}$, and $c d t \mathrm{C}$ genes in Campylobacter jejuni by multiplex PCR. Int. J. Med. Microbiol., v.296, p.45-48, 2006.

PERKO-MÄKELÄ, P.; ALTER, T.; ISOHANNI, P. et al. Distribution of Campylobacter jejuni isolates from Turkey farms and different stages at slaughter using pulsed-field gel electrophoresis and flaA-short variable region sequencing. Zoonoses Pub. Health, v.58, p.388-398, 2011. 
PEZZOTTI, G.; SERAFIN, A.; LUZZI, I. et al. Occurrence and resistance to antibiotics of Campylobacter jejuni and Campylobacter coli in animals and meat in northeastern Italy. Int. J. Food Microbiol., v.82, p.281-287, 2003.

POWELL, L.F.; LAWES, J.R.; CLIFTON-HADLEY, F.A. et al. The prevalence of Campylobacter spp. in broiler flocks and on broiler carcases, and the risks associated with highly contaminated carcases. Epidemiol. Infec., v.16, p.1-14, 2012.

QUERTZ, J.S.; LIMA, I.F.N.; HAVT, A. et al. Campylobacter jejuni and Campylobacter coli in children from communities in Northeastern Brazil: molecular detection and relation to nutritional status. Diagn. Micr. Infec. Dis., v.67, p.220-227, 2010.

ROZYNEK, E.; DZIERZANOWSKA-FANGRAT, K.; JOZWIAK, P. et al. Prevalence of potential virulence markers in Polish Campylobacter jejuni and Campylobacter coli isolates obtained from hospitalized children and from chicken carcasses. $J$. Med. Microbiol., v.54, p.615-619, 2005.
SAMUEL, M.C.; VUGIA, D.J.; SHALLOW, S. et al. Epidemiology of sporadic Campylobacter infection in the United States and declining trend in incidence, FoodNet 1996-1999. Clin. Infec. Dis., v.38, p.S165S174, 2004.

SCARCELLI, E.; GENOVEZ, M.E.; CARDOSO, M.V. et al. Avaliação do potencial de disseminação de Campylobacter spp. por diferentes espécies animais. Arq. Inst. Biol., v.65, p.55-61, 1998.

TOSIN, I.; MACHADO, R.A. Ocorrência de Campylobacter spp entre manipuladores de alimentos em cozinhas hospitalares de localidade urbana da Região Sul do Brasil. Rev. Saúde Públ., v.29, p.472477, 1995.

VAN DEUN, K.; HAESEBROUCK, F.; HEYNDRICKX, M. et al. Virulence properties of Campylobacter jejuni isolates of poultry and human origin. J. Med. Microbiol., v.56, p.1284-1289, 2007.

YOUNG, K.T.; DAVIS, L.M.; DIRITA, V.J. Campylobacter jejuni: molecular biology and pathogenesis. Nat. Rev., v.5, p.665-679, 2007. 